Western University Scholarship@Western

Aboriginal Policy Research Consortium International (APRCi)

$1-15-2008$

\title{
Cultural Icons and Marketing of Gambling
}

L. Dyall

S. Tse

A. Kingi

Follow this and additional works at: https://ir.lib.uwo.ca/aprci

Part of the International and Intercultural Communication Commons, Public Health Education and Promotion Commons, and the Substance Abuse and Addiction Commons

Citation of this paper:

Dyall, L.; Tse, S.; and Kingi, A., "Cultural Icons and Marketing of Gambling" (2008). Aboriginal Policy Research Consortium International (APRCi). 248.

https://ir.lib.uwo.ca/aprci/248 


\title{
Cultural Icons and Marketing of Gambling
}

\author{
L. Dyall $\cdot$ S. Tse $\cdot$ A. Kingi
}

Received: 9 September 2007 / Accepted: 13 December 2007 /

Published online: 15 January 2008

(C) Springer Science + Business Media, LLC 2007

\begin{abstract}
A number of different countries and states have or are in the process of developing formal or informal guidelines to govern gambling advertising and marketing of gambling. There is a growing consensus that gambling advertising should not mislead the public, be fair, provide information on the odds of wining and there should be provisions in place to protect vulnerable groups, such as, children. In the development of these guidelines by different countries or states there has been no real consideration of the need to engage with different indigenous and ethnic populations to ensure that they are protected as vulnerable populations. Further there is a need to engage with these populations within countries and across countries to ensure that indigenous and ethnic minority cultural icons, values, religious practices and music are not used without their permission or exploited in the business of promoting and marketing different forms of gambling products. New Zealand's experience of marketing and advertising of gambling is discussed in this paper. It is outlined the development of casinos in New Zealand and how Maori were actively encouraged to participate in the opening of these establishments and therefore, legitimate their existence as a safe place for Maori, the indigenous population of New Zealand to frequent on a regular basis. Since then other ethnic minority populations have been targeted to engage in different forms of gambling by recognising their significant cultural events, importance of family events and celebrating and promoting the success of important sport role models. Gambling advertising can be direct or subtle, however, little research has focussed on the third person effect associated with gambling advertising. New Zealand has adopted a public health approach to reduce gambling related harm. One of the key strategies introduced to reduce gambling related harm has been the development and
\end{abstract}

L. Dyall $(\square)$

Te Kupenga Hauora Maori, University of Auckland, Private Bag 92019, Auckland, New Zealand e-mail: 1.dyall@auckland.ac.nz

S. Tse

Centre for Asian Health Research and Evaluation, University of Auckland, Auckland, New Zealand

A. Kingi

Nui Development Inc., Auckland, New Zealand 
implementation of harm minimisation regulations. Research conducted in New Zealand regarding individuals' attitudes and behaviour to gambling, highlights that Maori have a high recall of gambling advertisements alongside other ethnic populations. The paper suggests that as part of a public health approach to reduce gambling related harm that it is now timely in New Zealand, for consideration to be given as to how much exposure, if any, New Zealanders should be subjected to gambling advertising.

Keywords Cultural icons and gambling $\cdot$ Indigenous $\cdot$ Ethnic populations and public health

\section{Introduction}

When approval was given in 1990 for the establishment of casinos in New Zealand, there was considerable excitement. It was believed then through the information presented to the public and the role of the Casino Control Authority, that these new gambling establishments, initially established in Christchurch (1994) and in Auckland (1996) would create considerable social and economic wealth and would enhance tourism. For Maori, the indigenous population, it was proposed that these new casinos would provide employment and new opportunities for economic development.

To celebrate the opening of these new gambling venues, Maori were invited and encouraged to place their cultural icons in these establishments. Large scale carvings were commissioned and placed in strategic entry points, to provide a sense of welcome and protection in the venues. Maori elders were also invited to use their cultural and spiritual rituals and processes to make these facilities safe for Maori and others to enter, so that they could come often and bring others to play on a regular basis. At the time of the opening of these casinos, no real consideration was given by Maori, either individually or collectively, that they were using their cultural beliefs and cultural symbols to actively promote the marketing and legitimatisation of casinos and at the same, reinforce the place of gambling $g$ in New Zealand society.

This paper will discuss the importance of protecting populations at risk from harm associated with marketing and promoting of gambling, utilising the New Zealand experience. It is proposed that specific ethnic communities should not be targeted to engage in gambling. Further, that their cultures, especially their values, cultural processes, spiritual beliefs, and special family occasions, should not be used as a means to promote and encourage these populations to engage in gambling, which then increases their risk of problem gambling and contributes generally to their low level of health and social, economic and cultural wellbeing.

It is proposed to support the development of a public health approach to remove gambling related harm, that there should be a specific harm minimisation regulation developed concerning marketing and advertising of gambling in New Zealand, instead of the current situation, where there exists a self regulatory code. At present, the code currently offers no real protection for Maori and ethnic minority communities who are harmed by gambling in New Zealand.

The paper outlines New Zealand's history and experience of gambling, it looks at international trends regarding the development of gambling advertising codes and the different roles that the media can play in both promoting the normalisation of gambling, as well as a vehicle to change values and attitudes towards gambling. The perceived third person effect of gambling advertising is discussed as well as research findings from New Zealand which identifies there are ethnic differences in regard to recall of gambling advertisements. 
In the past, New Zealand has been an international leader, on a number of important public health issues, such as, being first to allow women the right to vote, introducing legislation early to promote smoke free environments and to restrict tobacco advertising. With this history, it is proposed, that those involved in developing gambling harm minimisation regulations in New Zealand, should consider the recent initiative taken by the Auckland City Council to ban large scale billboards in the central city area. This decision was made that advertising can be hazardous and distracts people's attention from the physical and social environment that they live in. In general, the Auckland City Council has taken the view that large scale advertising pollutes the environment. Perhaps it is now timely, that consideration be given that gambling advertising pollutes New Zealand's social, cultural, environmental environments.

\section{Gambling in New Zealand and Harm Minimisation}

Gambling is now legalised through the Gambling Act 2003, in New Zealand. It is promoted as a legitimate recreational activity which provides considerable benefits to the community, especially by way of providing funding to assist a wide range of community, cultural and sports groups. Gambling provides revenue to support defined government agencies and to provide tax revenue to support Government priorities. The Gambling Act 2003 allows for legalised gambling. It imposes requirements to be met for different classes of gambling, especially for casinos and gambling machines. One of the purposes of the Act, is to remove gambling related harm from New Zealand and it was established after wide consultation and negotiation with different stakeholders, including political parties. All stakeholders have different views on the role, place and value gambling should play in New Zealand society.

The Act is very ambitious, has been operational for just over three years and it came fully into force, on 1 July 2004. A proposed amendment to the Act, is now before Parliament, to address technical issues which have emerged as a result of operation of the Act. One of the provisions within the Gambling Act 2003, is the requirement for locally elected councils to consult with Maori and other communities, to develop a specific gambling venue policy, at least every three years. This change has allowed for some degree of community voice in the placement of gambling venues. However, due to a statute provision, within the Act, the majority of "gambling machines", in communities cannot be removed. The Department of Internal Affairs on the other hand, is charged with responsibility to develop policy, to implement and monitor gambling harm minimisation regulations and to licence gambling operators.

To address health concerns regarding gambling, the Government has directed the Ministry of Health to purchase health services, with funding provided by specific gambling providers. They are: the New Zealand Racing Board, the New Zealand Lotteries Commission, gambling machine operators and casinos. Collectively, they compensate for the harm each creates in the community. The Gambling Commission an independent quasi judicial body recommends to the Government every three years the amount of funding that each industry, is required to pay for the harm they individually and collectively create in the community. This body provides advice on funding, however, the Government does not have to accept the advice offered by the Commission and it alone, can determine the level of fee each industry is to required to pay. Gambling advertising is linked to gambling harm, as messages are given to encourage individuals and communities to engage in different forms of gambling. 
New harm minimisation regulations are now in place in New Zealand, and are modelled on developments that have taken place in other countries, especially in Australia, which has focused on changing inside gambling environments. Casinos and gambling machine venues, for example, are now required to provide information to gamblers of the risks associated with gambling, the odds of winning, the amount spent and lost on an hourly basis, the signs and symptoms of problem gambling and information where gambling help services can be sought.

Gaming machines venues are also no longer able to the use the term "casino" in their name. The size of jackpots associated with gambling machines cannot be publicised outside of venues as a means to attract patrons. Despite these changes, there is no formal regulatory code of standards, governing advertising and marketing, even though there is provision under the Act if desired to, as part of harm minimisation. Instead, in New Zealand there is an Advertising Standards Association Code related to gambling advertising. This has been developed by the Advertising Standards Authority and is enforced by this body. The code is self regulatory and it states, that any form of gambling advertising should be socially responsible and should protect minors. No provisions, however, have been made within this code, to protect the cultural wellbeing of specific ethnic populations, especially Maori, the indigenous population of New Zealand.

In addition to the above code, there are a set of standards which governs "art works graphics", between Australian and New Zealand, regarding icons or symbols, which can be used on gambling machines. These graphic standards specifically state that artworks should not be pornographic nor create undue religious offence. This provision has allowed for the Department of Internal Affairs in 2003, to intervene following Maori advice, to request the removal of the use of a Maori poi (a traditional tool used in dance) from being used on gambling machines, on the basis, that this was spiritually and culturally offensive ${ }^{1}$.

As mentioned, the Gambling Act 2003, in New Zealand aims to reduce gambling harm and it defines, the legal age individuals can engage in different forms of gambling. The New Zealand Lotteries Commission, a Crown entity, for example, can only sell "Lotto" and other similar products to individuals over 16 years of age. These products are regularly sold in local shops and supermarkets and any new products or marketing of them are required to be reviewed by the Department of Internal Affairs and the Ministry of Health as to their general safety to young people and the public generally. This in house arrangement between government agencies is positive, however, as the Government is the major beneficiary, from revenue which flows from these products, it is considered that a more formal external review system should be in place. This is to ensure that the effects of regular advertising and promotion of gambling products on specific populations and communities are considered.

At present, the New Zealand Lotteries Commission, has no restrictions placed upon it as to "when", "where" and "how often", it can advertise its products. "Lotto" as a product depends upon constant advertising and is marketed regularly on national television and at times, when children and young adults are viewing television. The only legal parameters currently imposed on gambling providers in New Zealand, is that products advertised must comply with the requirements set out under that Fair Trading Act 1986, and in general advertisements must not be misleading, nor be deceptive to the public. Despite this requirement for fair trading, no information is regularly provided alongside the advertising

\footnotetext{
${ }^{1}$ Information provided by personal communication with Mr John Markland Manager Gaming Racing \& Censorship Policy, Department of Internal Affairs. 28 August 2007.
} 
of "Lotto", of the odds of winning the major prize or subsequent prizes. Furthermore, there are no restrictions placed upon advertising of the size of different Lotto jackpots and other games associated with this product. This situation is different from that of jackpots associated with gambling machines.

\section{Ethnic Populations in New Zealand and Gambling}

Currently, n New Zealand, there are different marketing strategies employed to introduce and promote gambling to specific ethnic populations. New Zealand has a unique population; it has a significant size indigenous population (Maori) which accounts for approximately $14 \%$ of the total population. It has a growing Asian population $(9.2 \%)$ with many recently settled and experiencing "culture shock" and a distinct Pacific population (6\%) with both New Zealand and Island born residents, who frequently visit home and have family members visit. Lastly, the majority of the population is Pakeha, a predominately European population, who brought gambling to New Zealand as part of their culture early in the 18th century,(Grant 1994). Since settling in New Zealand, Pakeha followed by other settlers, have used gambling as a recreational activity, a form of fund raising and now, a means to redistribute income from one group to another (Amey 2007).

Opportunities to gamble in New Zealand are not distributed evenly throughout all communities. Currently, casinos are based in four main cities (Auckland, Hamilton, Christchurch and Dunedin) and there are two in Queenstown, a major tourist destination. Gambling machines and the Totalisator Agency Board (TAB), which operates track and sports betting, are widely distributed throughout the country. The majority are located in low income communities. It is in these areas, where Maori, Pacific and increasingly Asian, are more likely to live, (Ministry of Health 2006a). Location of gambling venues in low income communities increases access and accentuates the vulnerability of marginalised populations to engage in gambling and therefore, increases their risk of gambling related harm. Pakeha or Europeans are also exposed to gambling in different communities, but in general, are more likely to live in areas which have a lower level of social deprivation and therefore, fewer opportunities to gamble.

Concentration of gambling venues in specific local communities not only increases those living in those areas the opportunity for gambling, but it also changes the local environment and therefore, influences local cultures and lifestyles practices. The sale and marketing of gambling products becomes part of the local culture, which can then capitalise on local social norms and become part of cultural and sport related activities. The promotion of "Lotto", in New Zealand, for example, is often linked to important family occasions, such as "Mother's or Father's Day" and "Christmas Day". Advertising is often focussed around the purchase of a Lotto ticket for a family member as a means for them individually and collectively, to achieve their family's dreams. For many low income families, with limited discretionary income, the giving of a "Lotto", ticket to a family member is a significant gift, but there are also real opportunity costs, money spent here, cannot be used elsewhere.

In the promotion of the encouraging individuals to purchase "Lotto", no information is provided to the purchaser or even the beneficiary of the ticket, of the statistical odds of winning a major prize. It will be recalled that this is a breach of one of the standards that are now considered should be in place to promote socially responsible gambling and fair trading of consumer products. 


\section{Sport: A Medium for Gambling Advertising}

Use of sport as a medium to promote gambling is a powerful form of gambling marketing in New Zealand. It is often used in subtle way to engage with Maori and Pacific and other communities. Many different forms of sport, are now linked to sports betting and in promoting these sports, such as rugby or rugby league, young Maori and Pacific men are clearly visible. To promote their sport and their sponsorship which shows clear links to gambling, such as Skycity Casino, they are often promoted in the media as sports heroes and also supporters of a specific form of gambling. When developing guidelines related to gambling advertising, the promotion of sport and sports heroes should be considered and protected, as such individuals are often seen in their communities as cultural icons and leaders for the future. Engagement and support of gambling by these sport heroes' validates gaming as an acceptable recreational activity and in doing so, supports others from their community to participate in wagering.

In New Zealand, gambling venues, are often used as meeting places, that is "to eat", "to drink" and "to celebrate wins and loses from sporting events". How these venues are used should be considered in the development of gambling marketing and advertising guidelines. This is important as often vulnerable groups are targeted to attend celebration gatherings in such settings and it is in these environments they are exposed to different forms of gambling. Furthermore they are often recruited by members of their social network or whanau to gamble or consume alcohol.

The intergenerational effect of gambling advertising has not been considered in the literature related to marketing and advertising of gambling but has links with the third person effect, which is discussed later. In New Zealand, many individuals are able to recall the promotion of gambling in their early childhood, by way of listening to the radio and seeing regularly on television horse racing and "Lotto", being drawn. This form of advertising has often occurred when they were young, most often with other family members being present. It is often family members who encourage young people to participate in gambling, for example, by asking help to pick winners or to contribute to the cost of purchasing of a lottery ticket. The intergenerational effects of marketing and promotion of gambling is visible when interviewing Maori who often state they were actively recruited to participate in gambling by way of family members, especially by grandparents, (Dyall and Hand 2003).

The above pattern continues today with New Zealand children being constantly exposed to gambling advertising in many different settings and this is often linked to sport or a major sport or track betting event, such as watching a major rugby game or horse racing event. Advertising of gambling is ever present on and off the sports field in New Zealand, with children and adults constantly together being informed of the odds of their favourite team winning or losing and therefore, the possibility of betting and winning additional cash. Gambling advertising on New Zealand television and in the media occurs with minimum restrictions. Therefore, it can be questioned as to whom is responsible for enforcing and monitoring the current voluntary code which governs gambling advertising in New Zealand.

\section{Gambling and Social Marketing: Another Form of Advertising}

One of the key interventions that have been introduced in New Zealand to reduce gambling related harm is a social marketing campaign. This campaign aims to improve the quality of life of New Zealanders by strengthening society's response to gambling and preventing and 
reducing gambling harm. Objectives of the programme are to: denormalise harmful gambling behaviour, enhance communities' capacity to define and address gambling issues, reduce exposure to harmful gambling opportunities, and increase understanding of gambling issues for all New Zealanders in relation to Te Tiriti o Waitangi. It is also intended to develop partnerships at local, national and international levels to reduce gambling harm.

The programme is funded by the Ministry of Health and has been contracted to the Health Sponsorship Council of New Zealand, a body with extensive experience in social marketing, to implement the campaign in 2007. The campaign has been developed in consultation with different stakeholder groups, including representatives from different ethnic populations.

To launch the campaign a simple message has been developed that is "problem gambling affects everyone in the community and problem gamblers come from all ethnic groups in New Zealand". A mainstream message has been developed showing ethnic faces of people who have been affected by problem gambling in New Zealand and in particular by playing gambling machines. The message aims to provide a warning, yet at the same time support the normalisation of gambling within New Zealand society, for alternative recreational activities are not promoted nor is information provided on the politics of gambling in New Zealand The campaign merely aims to provide support to those affected by problem gambling, to encourage those who need assistance to seek help and to increase the public's awareness of problem gambling. It is estimated that only $10-15 \%$ of those affected by problem gambling currently seek help in New Zealand. The campaign has increased attendance at gambling intervention services but the long term effectiveness of the program is unknown. However, as all forms of media have been used to implement the campaign inadvertently, it supports marketing and advertising of gambling, (Ministry of Health 2006b).

Different ethnic groups have questioned the effectiveness of the campaign and have challenged the notion of a generic message being used and translated for all major ethnic populations in New Zealand. Maori, for example, has challenged the effectiveness of the campaign and advocated as being indigenous they should be resourced to develop their own social marketing campaign, as tangata whenua (people of the land) they have been significantly affected by gambling related harm and this has occurred as part of the process of colonalisation, (Dyall 1998). A Maori social marketing to address the intrusion of gambling into Maori culture and wellbeing now needs to be developed to address gambling related harm for Maori. As a programme, it is likely to be different and not only focus on those affected by problems with gambling, but also focus on those stakeholders groups who have promoted gambling and created gambling related harm for Maori. If given the opportunity, this campaign, along with others developed by other ethnic groups in New Zealand, is likely to challenge the cultural values of Pakeha (Europeans) religious and sporting organisations and the Government generally which has promoted gambling, to become part of the culture fabric of New Zealand society, (Grant 1994).

Advertising and marketing of gambling, such as the promotion of "Lotto", has played an important role in allowing gambling to be embedded in New Zealand's culture and is now an integral part of many of New Zealanders' lifestyles and a means of coping with boredom, personal trauma and to create excitement in their lives, (Dyall and Hand 2003) Gambling advertising in New Zealand is now increasingly links to these triggers to gamble and messages are increasingly being developed to use gambling as a means to achieve lifestyle dreams, to become socially mobile and a means to socialise with others. No information as mentioned is provided alongside Lotto advertisements of the odds of 
winning. Again, there is a breach of not meeting now acceptable standards for socially responsible gambling.

\section{Advertising and Marketing of Gambling: International Trends}

Internationally, there is a growing interest and awareness that marketing and advertising of gambling should be socially responsive and should not target children or vulnerable people. A level playing field, for example, has also been proposed in England, in which different forms of gambling should have to meet defined advertising standards and if breached, complaints should be able to be referred to an independent body called the Gambling Commission for review, (Committee of Advertising Practice 2006). New advertising standards are planned to be in place in England in late 2007, to coincide with the implementation of the Gambling Act 2005. Following community and stakeholder engagement, it has been decided that gambling advertising should be socially responsible, not target children, young adults, vulnerable individuals and not mislead people to consider that gambling will solve financial issues or improve their sexual attractiveness. A voluntary self regulation code has been agreed to be administered by the Advertising Standards Authority linked to the Gambling Commission.

Queensland in Australia, has also developed guidelines to promote responsible gambling as part of this State's legislative requirements related to gambling and are based on the Australian Advertiser Code of Ethics adopted by the Australian Association of National Advertisers, (Queensland Office of Gaming Regulation 2005).

In Quebec, (Canada), specific advertising standards have been developed. For example, the odds of winning the State lottery must be clearly visible, children are not to be targeted, no particular group is to be targeted and any marketing of a new gambling product must involve advertising of the risks associated, (Korn 2000; Griffiths 2005).

In all three different localities there is a general agreement that gambling advertising should be fair, provide information on the odds of winning and should protect those who are vulnerable. The concept of vulnerability however, is not defined and thus each locality and those involved in gambling decision making have the authority to decide from their perspective as to who is vulnerable.

In all localities, however, there is no requirement to protect the cultural wellbeing of specific ethnic populations and to prohibit the use of their cultural symbols, images, music and cultural events, such as "Chinese New Year", in the marketing and advertising of gambling. This omission is of concern, as all three localities have different ethnic groups living within these regions and no provision has been made by Queensland and Quebec to protect their indigenous populations and ethnic communities in which where their culture plays a major role in protecting and enhancing their wellbeing. Ownership of intellectual property such as cultural icons and cultural events is a sensitive matter for indigenous and ethnic minority populations. The use of these icons and events without their approval by organisations marketing commercial products, is seen as disrespectful and a form of intellectual piracy, (Griggs 2001).

Increasingly, we are seeing in New Zealand the use of ethnic (e.g. image of dragon dance round the Chinese New Year festival) and Maori icons, (e.g use of native flora or fauna in promoting "scratch kiwi") being used in the promotion and marketing of gambling with no real ethnic input, approval and monitoring of agreements reached. To recognise the important relationship between health and culture as a determinant of wellbeing, countries or states developing guidelines for marketing and advertising of gambling should actively 
seek advice and input from their indigenous and ethnic populations to identify what protections they would like to see in place for their people, (Durie 2004).

They should be asked as to how they would like or not want their culture values and icons being used in the promotion and marketing of gambling. Further, they should be consulted to identify the extent marketing and advertising of gambling should be allowed to be present and linked to their culture. For example, should gambling, be able to capitalise on specific ethnic cultural events. At present "red pockets" are often used by Chinese families to give money to each other to promote their good health and wellbeing at Chinese New Year. This event has been capitalised in New Zealand and taken and used by a gambling provider as a means to promote itself as place to visit, a place to gamble and a place to consume alcohol with the offer of free drink vouchers by the use of "red pocket". The icon of the Chinese dragon has also been used part of their marketing to coincide with Chinese New Year. This form of marketing has occurred in a context where it is known that specific Asian communities are at risk from harm from casino gambling. Similar activities have also occurred linking with Pacific peoples' focussing on food and music. Lack of consultation to date in New Zealand with Maori and specific ethnic communities has meant that these communities have been unable to define the ground rules as to how their culture and special cultural events should be respected and protected from the business of gambling.

An open approach regarding marketing and advertising of gambling places special responsibilities on those agencies which have responsibilities for gambling policy, licensing and regulation of legalised gambling. In New Zealand, there should be greater engagement with indigenous and ethnic communities as to their how their cultures and cultural icons are used and protected in the business of gambling.

\section{Third Person Effect}

Despite recognition of the power of advertising, there has been little research conducted to determine the influence gambling advertising has on peoples' attitudes and gambling behaviour. Research conducted in relation to the advertising of legal products such as tobacco or alcohol, has found that when interviewing people as to whether there should be restrictions in advertising related to alcohol or tobacco, there has been strong support for restrictions to protect "others". This has been defined and described as the "third person effect", in that people are likely to consider that others are more affected by persuasive advertising and marketing than themselves and on that basis, are supportive of restrictions to protect "others".

Research which has tested this assumption in relation to casino and lotto advertising has found that the third person effect does apply and from one study, it was found that there was greater support for the protection of adults than children. From the findings of this study, researchers suggest that participants considered that adults more than children, are more likely to be influenced by gambling advertising, which then affects their attitudes and behaviour towards gambling and possibly, increases their the level of harm from gambling. Casino advertisements were considered to be more influential than lottery advertisements, with women being more supportive of protecting others, (Youn et al. 2000).

A number of different reasons have been given to explain these findings. It has been suggested that the term children may have been interpreted differently by participants, with some considering the term related to those in elementary school, where as others, may have 
considered the term widely and included those from preschool to high school. Overall, it was concluded that respondents were likely to consider what protections are already in place for children, the likelihood of them gambling and current restrictions in place to limit gambling harm. Although the findings of this study are important, researchers caution using this study as the basis for developing media censorship policy as more information is needed to understand fully the third person effect, before developing effective policies to provide consumer protection,(Youn et al. 2000).

On the other hand, lottery operators are aware that marketing and advertising, especially through television, plays an important role in reaching a broad audience and promoting the regular sale and growth of lottery products. Television screening of gambling results, such as the weekly lottery and daily keno increases visibility of gambling and in some situations, allows winners to be highly visible and for losers to be invisible. These types of shows are part of advertising and marketing of gambling and they are regularly watched by wide audiences and often with children watching.

As well as this form of advertising increasingly, there are television programs being commissioned which encourage individuals to compete in different intellectual games such as quizzes, which tests their knowledge and risk taking behaviour in being able to win or lose dollars for themselves or on behalf of different charity groups. Exposure and watching television varies in communities and it has been found that those on low incomes are likely to watch television more than other income groups and therefore, subject to greater exposure to gambling advertising than other income groups.

Research has found overseas and in New Zealand, that those on low incomes spend a greater proportion of their income on gambling than other income groups, are more likely to be influenced by gambling advertising and have a higher prevalence of problem and pathological gambling, Ministry of Health 2006a). New data released in New Zealand has identified that although access to gambling machines in the community has reduced, there has been an increase in the number of people seeking help with problems associated with casinos, (Ministry of Health 2007). This increase may be related to regular advertising by local casinos, such as Skycity, which regularly promotes itself on television as a place to visit for an evening out.

\section{Marketing and Advertising of Gambling in New Zealand}

Increasingly, there is growing awareness that gambling advertisements should be truthful, honest and have to meet defined standards which protect consumers from false advertising. Work is underway in New Zealand by key gambling stakeholders to review gambling advertising and to propose a new voluntary code of practice to counteract growing concerns that there should be restrictions on the marketing and advertising of gambling, consistent with the requirement to develop harm minimisation regulations.

Several studies with common methodology have been conducted in New Zealand which highlight that gamblers are aware of advertising. The most recent study was undertaken in 2000 and involved 1,500 participants, (Department of Internal Affairs 2001). One of the areas surveyed was participants' awareness and attitudes towards gambling advertisements. For all participants, the majority could recall gambling advertisements especially those funded by the New Zealand Lotteries Commission which run Lotto, daily keno, scratch kiwi and other products. Those who played the pokie machines had the greatest recall. Men could recall more than women and those who were significantly engaged in gambling were more likely to recall gambling advertisements. 
Ethnic differences also emerged, in which Maori had a higher recall than non Maori (Pakeha) for track betting advertisements and had the least knowledge as to whom benefited from legalised gambling in New Zealand. Pacific participants also had a high recall of advertisements, especially in relation to casino messages where as Maori had a lower recall. The pattern of recall, mirrors the prevalence of problem gambling in New Zealand, with Maori having four times the risk of being affected by gaming than non Maori (Europeans) and for Pacific their risk is six fold,(Abbott 2001; Ministry of Health 2006b).

Currently, with the exception of casinos, legalised gambling exists in New Zealand to provide funding as a "community good". This funding provides support to many different community groups and activities. It also supports the development and maintenance of Maori cultural heritage, such as development of marae (meeting place) or associated facilities and funding has just recently been allocated to support Pacific community and cultural developments. As specific forms of gambling have now been legalised for the sole purpose to provide community benefit, it can be questioned, "why do communities and populations should have to be subjected to gambling marketing, advertising and the potential harms caused by gambling?"

Being subjected to and exposed to gambling advertising without any choice or any protections in place, it can be argued on the evidence available, that this is hazardous in New Zealand and can be considered a form of environmental pollution. This perspective sounds radical, however, just recently, the Auckland City Council, governing the largest city in New Zealand, has made a decision to develop a bylaw to remove from the public's eye all large billboards and other forms of advertising in the city area, (Thompson 2006). The Council's decision has been made on the basis that large scale commercial advertising competes with and distracts the viewer's eye away from their physical surroundings and devalues the natural beauty and cultural heritage of Auckland city. This decision has been challenged by many organisations dependent upon commercial advertising. The decision to remove, however, has made on the basis of the collective interests of Auckland, to develop this city to a high international standard.

The same analogy can be applied to gambling and it can be asked, "why does the general public in New Zealand has to be exposed and subjected to gambling advertising?". Currently, legalised gambling in New Zealand as mentioned exists mainly to provide a community benefit and as a consequence, many community groups are now reliant upon this form of funding to support their activities, (Amey 2007).

To receive gambling funding, some gambling charitable trusts and the New Zealand Lottery Grants Board encourage community groups to promote gambling in a subtle way. For example, they encourage some sports groups to promote their logo on their sports uniform or in their advertising, recognition of their sponsorship. It is also common to see on different community initiated buildings, such as marae or associated facilities, a plague which acknowledges the support that has been given by the New Zealand Lotteries Board or a charitable gambling trust.

At the same time community groups are actively by the Department of Internal Affairs to actively apply for gambling funding, even though funding may have been taken from poorer communities to fund activities in higher income communities. To reduce reliance on gambling funding a community led organisation called the "Gambling Watch Coalition", has developed a public awareness campaign to encourage community groups not to take gambling funding to support their activities, therefore, not become reliant and dependent upon gambling funding, (Gambling Watch 2004).

At present, there is some degree of conflict of interest in the roles and responsibilities of the Department of Internal Affairs, the Government's agency responsible for gambling in 
New Zealand. This agency has responsibility for the development of regulations, monitoring and licensing of gambling in New Zealand and to date has focussed on changing the environment and culture within gambling venues. It is considered that it is now timely for this agency, to recognise its responsibilities to Maori as a treaty partner with the Crown, which gives tangata whenua defined rights and places responsibilities on government agencies to protect and enhance the wellbeing of Maori firstly, and then other citizens.

It is argued that as gambling has become an integral part of the culture of being Maori, supported by advertising and marketing of gambling that the Department of Internal Affairs should take a leadership role and develop a statutory defined code, possibly by way of regulation, which is socially responsible and clearly defines how gambling products should be marketed and which protects indigenous and ethnic populations cultural icons, cultural values, music and cultural activities.

This initiative would address the current imbalance of power, in which gambling industries define from their perspective as to whom is vulnerable and what is socially responsible gambling. Alternatively, the Department of Internal Affairs with government support could take a similar approach as the Auckland City Council to ban all forms of gambling advertising and marketing on the basis that it encourages gambling and for many individuals and ethnic communities, gambling creates harm.

\section{Conclusion}

New Zealand currently has an unregulated environment in relation to gambling marketing and advertising even though as a country, it has been involved in developing a public health approach to address gambling related harm. There is potential within the Gambling Act 2003, in New Zealand for the Department of Internal Affairs to take a leadership role with Government support, to develop more formal rules related to gambling marketing and advertising, as part of its statutory requirements to develop harm minimisation regulations.

Lessons can be learnt from other countries which have developed gambling advertising guidelines in that they have failed to consider the need to protect indigenous and ethnic monitories cultural icons, heroes, values, music and events which are important to their cultural and spiritual wellbeing. Intellectual piracy of cultural icons should be considered in the area of gambling and safeguards should be in place to ensure that cultural icons are not used in gambling without the approval of specific ethnic populations. One situation has already occurred where there existed the possibility of gaming machines manufacturers coopting without approval the use of the Maori poi.

In the development of gambling advertising guidelines, indigenous and ethnic groups should be involved in the development and implementation of them, so that they are actively involved in determining who is vulnerable, how their children should be protected and what is fair and responsible gambling from their perspective. In New Zealand, there should also be consideration as to whether all forms of gambling advertising should be outlawed, for gambling largely exists to provide community benefit. Further, New Zealanders can now ask similar questions as those which were considered by the Auckland City Council. On behalf of Auckland rate payers this body has decided that commercial advertising by way of large billboards is a form of environmental pollution as it detracts away from the beautiful natural surroundings of New Zealand.

As a country New Zealand prides itself internationally on its image, as a clean green country. Perhaps this analogy now needs to be taken into the area of gambling, in which it 
is time now to clean up gambling advertising in our communities and develop a coherent response to gambling advertising. It is argued that we should not leave key stakeholders with a vested interest in gambling to develop guidelines on gambling advertising. Instead, the Department of Internal Affairs should be required to engage with Maori and other ethnic groups as to how gambling advertising should be regulated so that gambling does not invade further into changing our culture, our values and lifestyles and furthermore, our cultural icons are not exploited in the business of gambling.

\section{References}

Abbott, M. (2001). What do we know about gambling and problem gambling in New Zealand. Wellington: Department of Internal Affairs.

Amey, B. (2007). Where do gaming machine profits go? A survey of the allocation for authorised purposes of non-casino gaming machines profits in 2005. Wellington: Department of Internal Affairs.

Committee of Advertising Practice (2006). Gambling Advertising Consultation Launched. London: http:// www.cap.org.uk/cap/news-events/news.

Department of Internal Affairs (2001). People's participation in and attitudes to gaming 1985-2000 final results of the 2000 survey. Wellington: Department of Internal Affairs.

Durie, M. (2004). Understanding health and illness: research at the interface between science and indigenous knowledge. International Journal of Epidemiology, 33, 1138-1143.

Dyall, L. (1998). Treaty of Waitangi and gambling. National Workshop On Treatment For Problem Gambling, Auckland, Compulsive Gambling Society of New Zealand Inc.

Dyall, L., \& Hand, J. (2003). Maori and gambling: why a comprehensive Maori public health response is required in Aotearoa. eCommunity International Journal of Mental Health \& Addiction, 1(1), 1-16.

Gambling Watch (2004). Social movement approach needed to raise problem gambling awareness in New Zealand. Hamilton: New Zealand Press Association.

Grant, D. (1994). On a roll: a history of gambling and lotteries in New Zealand. Wellington: Victoria University Press.

Griffiths, M. (2005). Does gambling advertising contribute to problem gambling. eCommunity International Journal of Mental Health \& Addiction, 3(2), 15-25n.

Griggs, K. (2001). Maori take on hi-tec Lego. BBC News, 26 October 2001 http://news, bbc.co uk/2hi/ asiapacific/169406.stm.

Health Sponsorship Council (2007). Problem gambling mass media campaign-stakeholder feedback June 2007. Wellington: Health Sponsorship Council (unpublished).

Korn, D. (2000). Expansion of gambling in Canada: implications for health and social policy. Can Med Ass $J, 163(1), 61-64$.

Ministry of Health (2006a). Problem Gambling Geography Report. Wellington.

Ministry of Health (2006b). Problem Gambling in New Zealand Analysis of the 2002/03 New Zealand Health Survey. Wellington: Ministry of Health.

Ministry of Health (2007). Problem Gambling Intervention Services in New Zealand 2006 Service-user statistics. P. H. I. M. R. No.14. Wellington.

Queensland Office of Gaming Regulation (200 BB5). Queensland Responsible Gambling Advertising and Promotion Guidelines. Brisbane, Queensland Office of Gaming Regulation http:/www.responsiblegambling. qld.gov.au.

Thompson, W. (2006). Billboard Wins Council Endorsement. New Zealand Herald.

Youn, S., Faber, R., et al. (2000). Restricting Gambling Advertising and the Third Person Effect. Psychology \& Marketing, 17(7), 633-649. 